\title{
Review of topographic analysis methods for the western Himalaya using AWiFS and MODIS satellite imagery
}

\author{
V.D. MISHRA, ${ }^{1}$ J.K. SHARMA, ${ }^{2}$ R. KHANNA ${ }^{3}$ \\ ${ }^{1}$ Snow and Avalanche Study Establishment (SASE), Him Parisar, Sector 37A, Chandigarh 160036, India \\ E-mail:vdmishra@rediffmail.com \\ ${ }^{2}$ Rayat Institute of Engineering and Information Technology, Railmajra, Near Ropar, Distt. Nawanshahr, Punjab 144533, India \\ ${ }^{3}$ Electronics and Communication Engineering, Thapar University, Patiala 147004, India
}

\begin{abstract}
The topographic effects of differential terrain illumination in optical satellite imagery of rugged mountainous regions have serious consequences for qualitative and quantitative analysis for various snow applications. Therefore, effective removal or minimization of topographic effects is necessary in satellite image data of mountainous regions. Different methods for topographic corrections, including C-correction, Minnaert corrections (including slope) and slope-matching method, are analysed in the context of snow reflectance. Combination of dark-object subtraction models DOS1 and DOS3 is used for image-based atmospheric corrections while considering the effect of Rayleigh scattering on the transmissivity in different spectral bands of AWiFS and MODIS image data. The performance of different models is evaluated using (1) visual analysis, (2) change in snow reflectance on sunny and shady slopes after the corrections, (3) validation with in situ observations and (4) graphical analysis. The results show that the slope-matching technique could eliminate most of the shadowing effects in Himalayan rugged terrain and correctly estimate snow reflectance from AWiFS and MODIS imagery. The validation of results with in situ observations for both types of imagery suggests that all other methods significantly underestimate reflectance values after the corrections.
\end{abstract}

\section{INTRODUCTION}

Scientific studies using remote-sensing data in the past were primarily focused on land-use classification and long-term temporal changes in terrestrial land cover, assuming flat terrain in order to avoid complexities due to topography (Sandmeier 1995). The strong variations in topographical parameters (mainly slope, aspect and altitude) in rugged mountainous terrain significantly influence the qualitative and quantitative analysis of snow cover (Dozier and Marks, 1987). The relief effect due to topography is neither eliminated during system correction nor during the normal geometric correction and has great significance in mountainous regions. Therefore, the impact of topography must be carefully examined prior to interpretation of remote-sensing data for snow-cover applications.

Various topographic correction methods are reported in the literature (Riaño and others, 2003; Nichol and others, 2006), including cosine-law method, C-correction, Minnaert corrections and slope matching. However, these have not been explored very extensively for snow-cover applications in Himalayan terrain. Most research is focused exclusively on vegetation analysis (Riaño and others, 2003; Nichol and others, 2006).

In this study, we carry out an extensive comparative performance analysis of different topographic normalization methods for snow-cover applications in rugged Himalayan terrain using Advanced Wide Field Sensor (AWiFS) and Moderate Resolution Imaging Spectroradiometer (MODIS) satellite data. The main objectives in the present paper are (1) qualitative performance analysis, (2) quantitative analysis of snow reflectance after topographic corrections, (3) validation of the spectral reflectance with in situ observations and (4) graphical analysis. Image-based atmospheric correction (Chavez, 1989; Song and others, 2001) for path radiance and Rayleigh scattering is performed first for initial estimation of spectral reflectance without considering topographic influences. The details of implementation of these corrections on satellite imageries are reported by Mishra and others (2009).

\section{TOPOGRAPHIC MODELS: A BRIEF REVIEW}

Image-based atmospherically corrected target spectral reflectance on the tilted surface, $R_{\lambda \mathrm{T}}$, from sensor radiance, $L_{\lambda}$, is obtained using the following model (Pandya and others, 2002; Shepherd and Dymond, 2003):

$$
R_{\lambda \mathrm{T}}=\frac{\pi\left(L_{\lambda}-L_{\mathrm{p}}\right) d^{2}}{t_{v}\left(E_{0} \cos \theta_{z} t_{z}+E_{\mathrm{d}}+E_{\mathrm{t}}\right)}
$$

where $L_{\mathrm{p}}$ is the path radiance in $\mathrm{mW} \mathrm{cm}^{-2} \mathrm{sr}^{-1} \mu \mathrm{m}^{-1}$ and estimated according to Moran and others (1992), and $d$ is the Earth-Sun distance in astronomical units and calculated using the approach of Van der Meer (1996). $E_{0}$ is bandpass exoatmospheric spectral irradiance (Tables 1 and 2), $E_{\mathrm{d}}$ is downwelling spectral irradiance at the surface due to diffused radiation and assumed equal to zero according to Chavez (1989), $\theta_{z}$ is the solar zenith angle and calculated (Kasten, 1962) for each pixel of the study area, $t_{v}$ is atmospheric transmittance along the path from ground surface to sensor and $t_{z}$ is atmospheric transmittance along the path from Sun to ground (Table 3) and calculated for the AWiFS and MODIS spectral bands using the model (Pandya and others, 2002). The parameter $E_{\mathrm{t}}$ is the terrain irradiance contributed due to reflected radiation from the adjacent terrain. The effect needs to be included in topographic correction for satellite data with fine spatial resolution (Liu and others, 2009). In case of coarse spatial resolution, it is negligible (Richter, 1998), so it is not considered in the present work for AWiFS and MODIS satellite data. 
Table 1. Salient specifications of AWiFS sensor

\begin{tabular}{|c|c|c|c|c|c|}
\hline \multirow{2}{*}{$\begin{array}{l}\text { AWiFS band (spectral } \\
\text { reflectance) }\end{array}$} & Spatial resolution at nadir & Quantization & Min. radiance & Max. radiance & $\begin{array}{c}\text { Mean solar exoatmospheric } \\
\text { spectral irradiance }\end{array}$ \\
\hline & $\mathrm{m}$ & bits & $\mathrm{mW} \mathrm{cm}^{-2} \mathrm{Sr}^{-1} \mu \mathrm{m}^{-1}$ & $\mathrm{~mW} \mathrm{~cm}^{-2} \mathrm{Sr}^{-1} \mu \mathrm{m}^{-1}$ & $\mathrm{~mW} \mathrm{~cm}^{-2} \mu \mathrm{m}^{-1}$ \\
\hline B2 $(520-590 \mathrm{~nm})$ & 56 & 10 & 0 & 52.34 & 185.3218 \\
\hline B3 $(620-680 \mathrm{~nm})$ & 56 & 10 & 0 & 40.75 & 158.042 \\
\hline B4 (770-860 nm) & 56 & 10 & 0 & 28.425 & 108.357 \\
\hline B5 (1550-1700 nm) & 56 & 10 & 0 & 4.645 & 23.786 \\
\hline
\end{tabular}

\section{Cosine law}

Cosine law is the most commonly used method and is based on a trigonometric approach assuming the surface to be Lambertian. The spectral reflectance is computed as (Teillet and others, 1982)

$$
R_{\lambda \mathrm{H}}=R_{\lambda \mathrm{T}}\left(\frac{\cos \theta_{\mathrm{z}}}{\cos i}\right)
$$

where $R_{\lambda H}$ is spectral reflectance for a horizontal surface, $R_{\lambda \mathrm{T}}$ is spectral reflectance observed over inclined terrain and $\cos i$ is illumination (IL) and calculated using the equation proposed by Civco (1989).

\section{C-correction}

C-correction is based on the assumption of a nonLambertian surface and is a modification of cosine correction developed by Teillet and others (1982). A quantity, $c_{\lambda}$, is introduced into Equation (2) defined as:

$$
R_{\lambda \mathrm{H}}=R_{\lambda \mathrm{T}}\left(\frac{\cos \theta_{\mathrm{z}}+c_{\lambda}}{\cos i+c_{\lambda}}\right),
$$

where $c_{\lambda}=\left(b_{\lambda} / m_{\lambda}\right)$ is a quotient between intercept $\left(b_{\lambda}\right)$ and slope $\left(m_{\lambda}\right)$ in different spectral bands. It is estimated using a regression equation assuming the linear relationship between original uncorrected reflectance and $\cos i$ as:

\section{Minnaert methods}

$$
R_{\lambda \mathrm{T}}=m_{\lambda} \cos i+b_{\lambda} .
$$

Minnaert methods are non-Lambertian and based on the ideas of Minnaert (1941) who first proposed a semiempirical equation to assess the roughness of the Moon surface. The function has been used for photometric analysis of lunar surfaces (Holben and Justice, 1980) and implemented for topographic corrections as follows:

$$
R_{\lambda \mathrm{H}}=R_{\lambda \mathrm{T}}\left(\frac{\cos \theta_{\mathrm{z}}}{\cos i}\right)^{k(\lambda)}
$$

where $k(\lambda)$ is the Minnaert constant and depends on the type of surface and spectral wavelength bands. It varies from 0 (ideally non-Lambertian surface) to 1 (perfect Lambertian surface). Equation (4) was further modified by Colby (1991) to include terrain slope, $\theta_{\mathrm{p}}$, as follows:

$$
R_{\lambda \mathrm{H}}=R_{\lambda \mathrm{T}} \cos \theta_{\mathrm{p}}\left(\frac{\cos \theta_{\mathrm{z}}}{\cos i \cos \theta_{\mathrm{p}}}\right)^{k(\lambda)} .
$$

The value of $k(\lambda)$ can be determined by linearizing Equation (5).

\section{Slope-matching method}

The slope-matching method was proposed by Nichol and others (2006) who introduced certain modifications to Civco's (1989) model and considered the topographic corrections in two stages. They observed that Civco's (1989) topographic corrections do not improve the results in shady areas. In order to enhance the results on the northfacing slopes in the shadow area, equalization of radiance is required with respect to Sun-facing slopes to make the extent of corrections equal to the maximum difference of radiance values on both aspects. The final reflectance for topographic correction by Nichol and others (2006) is estimated using:

$$
R_{\mathrm{n} \lambda \mathrm{ij}}=R_{\lambda \mathrm{ij}}+\left(R_{\max }-R_{\min }\right) \frac{\left[\langle\cos i\rangle_{\mathrm{s}}-\cos \mathrm{ij} i\right]}{\langle\cos i\rangle_{\mathrm{s}}} C_{\lambda},
$$

where $R_{\mathrm{n} \lambda \mathrm{ij}}$ is the normalized reflectance values for image pixel ij in waveband $\lambda, R_{\lambda \mathrm{ij}}=R_{\lambda \mathrm{T}}$ is the uncorrected original reflectance on the tilted surface for image pixel ij in waveband $\lambda, R_{\max }$ and $R_{\min }$ are the maximum and minimum reflectance values, $\langle\cos i\rangle_{\mathrm{s}}$ is the scaled (0-255) mean IL on the south aspect and $C_{\lambda}$ is the coefficient estimated for each AWiFS and MODIS spectral band using the equation proposed by Nichol and others (2006). The slope-matching method adjusts the brightness between northern and

Table 2. Salient specifications of MODIS sensor

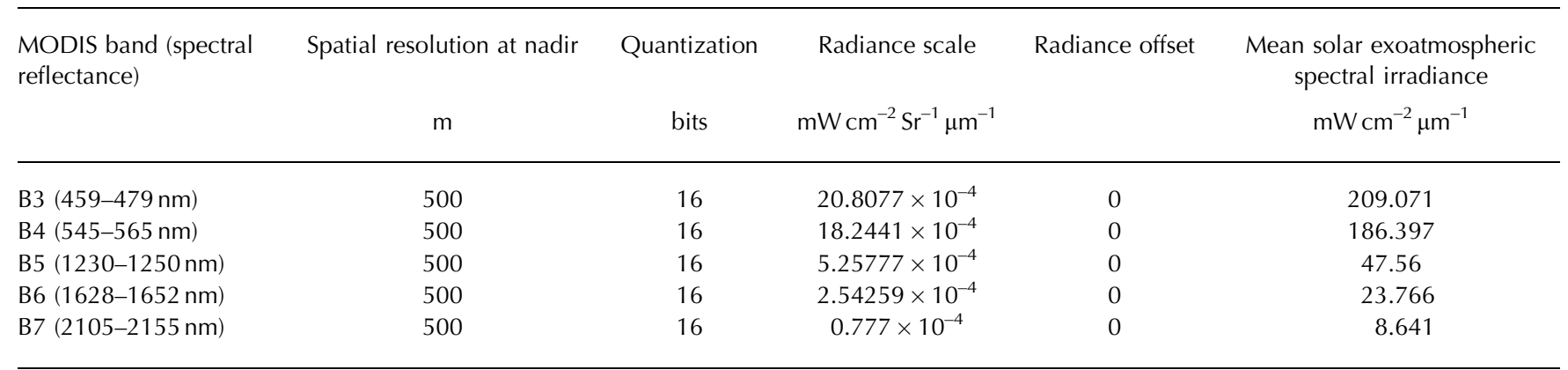



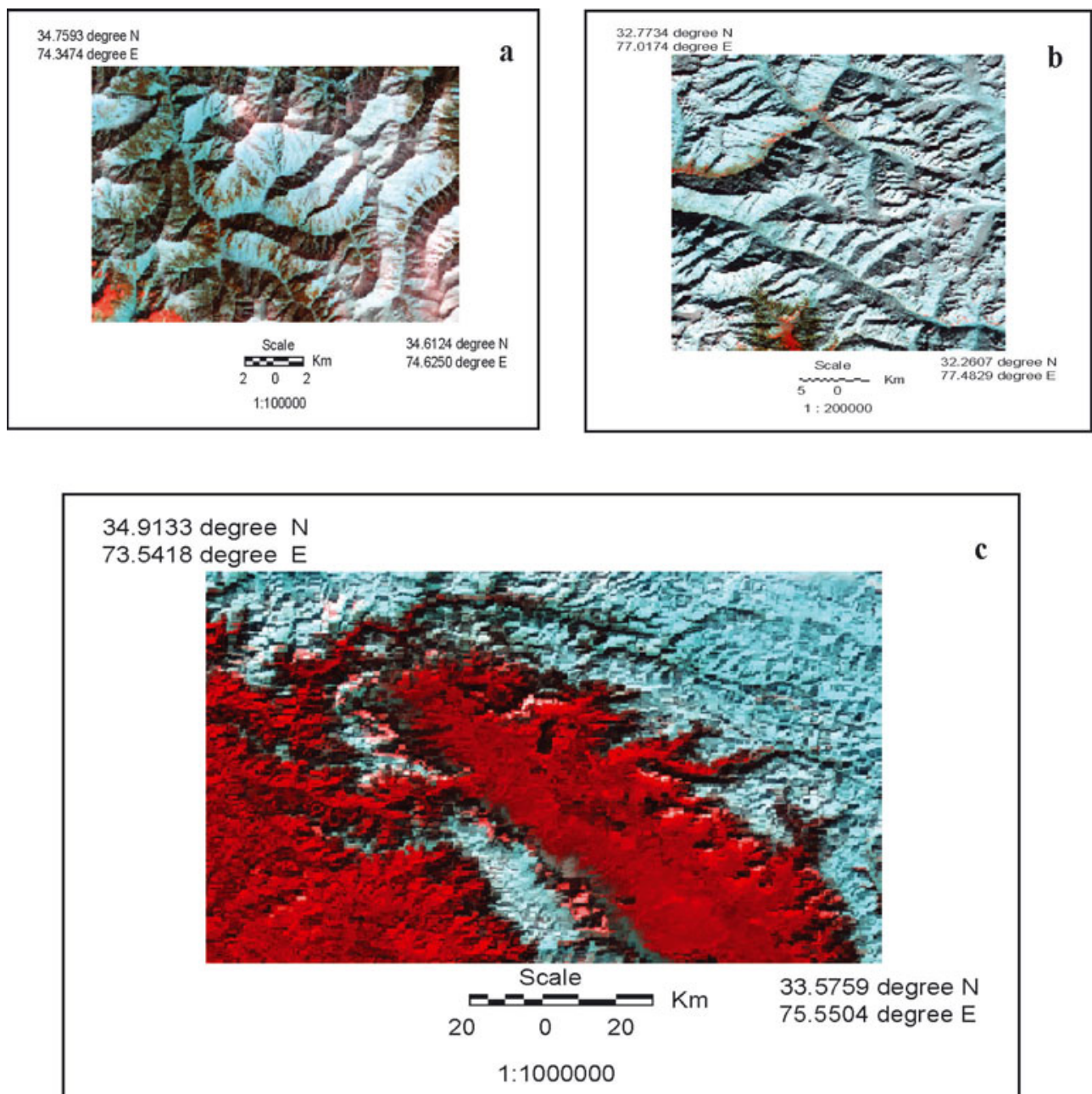

Fig. 1. False-colour composite (FCC) images of the three study areas on (a, b) AWiFS sensor (bands 2, 3 and 5) of 26 February 2005 and 8 January 2009 and (c) MODIS sensor (bands 3, 4 and 6) of 19 January 2005.

southern slopes. As such, its parameters depend on the image itself. It may perform very well for in-image adjustments, but its results may not be comparable between different images, as each image has its own statistics.

\section{METHODOLOGY}

\section{Study area}

Three study areas are considered in the present work. The first is located at $34.6124-34.7593^{\circ} \mathrm{N}, 74.3474-74.6250^{\circ} \mathrm{E}$ in the northeast tip of the Shamsabari range in the Jammu and
Kashmir (J\&K) region of the western Himalaya (Fig. 1a). The maximum elevation is $4101 \mathrm{~m}$, with an average value of $3090 \mathrm{~m}$. The slope of the area varies from $0.17^{\circ}$ to $69^{\circ}$, with an average value of $27^{\circ}$. The second study area is located at 32.2607-32.7734 ${ }^{\circ} \mathrm{N}, 77.0174-77.4829^{\circ} \mathrm{E}$, covering part of Beas basin in the Kullu district of Himachal Pradesh (Fig. 1b). The maximum altitude varies from 1900 to $6500 \mathrm{~m}$, with an average elevation of $4570 \mathrm{~m}$. The average slope of this area is about $30^{\circ}$. The third study area (Fig. 1c) covers different Himalayan ranges, the Pir Panjal, Shamsabari and Greater Himalaya, and is located at 33.5759-34.9133 ${ }^{\circ} \mathrm{N}, 73.5418$ $75.5504^{\circ} \mathrm{E}$. The maximum altitude is $5480 \mathrm{~m}$, with an

Table 3. Atmospheric transmissivity in different spectral bands of AWiFS and MODIS

\begin{tabular}{|c|c|c|c|c|c|}
\hline $\begin{array}{l}\text { AWiFS band (spectral } \\
\text { reflectance) }\end{array}$ & $\begin{array}{l}\text { Upwelling atmospheric } \\
\text { transmissivity, } t_{v}\end{array}$ & $\begin{array}{c}\text { Downwelling } \\
\text { atmospheric } \\
\text { transmissivity, } t_{z}\end{array}$ & MODIS & $\begin{array}{c}\text { Upwelling } \\
\text { atmospheric } \\
\text { transmissivity, } t_{v}\end{array}$ & $\begin{array}{c}\text { Downwelling atmospheric } \\
\text { transmissivity, } t_{z}\end{array}$ \\
\hline B2 $(520-590 \mathrm{~nm})$ & 0.935 & 0.911 & B3 (459-479) & 0.879 & 0.822 \\
\hline B3 $(620-680 \mathrm{~nm})$ & 0.965 & 0.952 & B4 (545-565) & 0.937 & 0.906 \\
\hline B4 $(770-860 \mathrm{~nm})$ & 0.986 & 0.980 & B5 (1230-1250) & 0.997 & 0.996 \\
\hline \multirow[t]{2}{*}{ B5 (1550-1700 nm) } & 0.999 & 0.998 & B6 (1628-1652) & 0.999 & 0.998 \\
\hline & & & B7 (2105-2155) & 0.999 & 0.999 \\
\hline
\end{tabular}


Table 4. Coefficients for different topographic normalization models. Values are in AWiFS and MODIS band ascending order

Satellite image

Coefficients

C-correction

Minnaert constant

$0.54,0.54,0.54,0.35$

$0.35,0.38,0.40,0.35$

AWiFS, 26 Feb. 2005

AWiFS, 8 Jan. 2009

$0.224,0.284,0.300,0.651$

$2.92,2.74,2.64,2.73$

MODIS, 19 Jan. 2005
$0.23,0.28,0.32,0.33,0.33$
Slope match average value of $2482 \mathrm{~m}$. The average slope here is $23^{\circ}$. In general, these areas are densely forested between 2400 and $3100 \mathrm{~m}$ a.s.l. Beyond $3100 \mathrm{~m}$, forest is scanty; however, the parts below $2400 \mathrm{~m}$ are forested. The areas of interest have been selected to cover a broad range of terrain features and geomorphology. The analysis has been carried out to evaluate the performance of different topographic models in different geographic regions to ensure their successful implementation over a wide range of hilly terrain.

\section{Satellite data}

Two almost cloud-free scenes of the AWiFS sensor, on board IRS-P6 (RESOURCESAT-I), of 26 February 2005 (Fig. 1a) and 8 January 2009 (Fig. 1b), with spatial resolution of $56 \mathrm{~m}$, and a third of the MODIS sensor, on board the Terra satellite, of 19 January 2005 (Fig. 1c) in spectral bands 3-7 at $500 \mathrm{~m}$ spatial resolution are used in the present work. The selection criteria for these scenes are acquisition at low solar elevation $\left(45.5^{\circ}\right.$ for Fig. $1 \mathrm{a}, 33.4^{\circ}$ for Fig. $1 \mathrm{~b}$ and $33.5^{\circ}$ for Fig. $\left.1 \mathrm{c}\right)$ and availability of real-time in situ field data. The field observations of snow spectral characteristics were recorded in the complete solar wavelength range 350-2500 nm using optical spectroradiometer at the time of satellite passes. These field results are used for validation with satellite-estimated spectral reflectance in AWiFS and MODIS spectral bands after different topographic corrections. The salient specifications of AWiFS and MODIS sensor bands are given in Tables 1 and 2 .

\section{Geometric corrections}

The master data were prepared first by rectifying higher spatial resolution $(23.5 \mathrm{~m})$ images of the Indian Remotesensing Satellite (IRS) LISS-III (Linear Imaging Self-Scanning) sensor with the Survey of India (Sol) maps of different study areas. Thereafter, AWiFS images were georeferenced with LISS-III images. Similarly, moderate-resolution $(500 \mathrm{~m})$
MODIS data were rectified using medium-resolution (56 m) AWiFS images. The image rectification was further refined using IL images. This step is essential to ensure that the satellite images used for topographic corrections match with topographical information generated using Sol maps to avoid erroneous results. The nearest-neighbor resampling method was used and the geolocation error of the model is about half a pixel.

\section{Digital elevation model (DEM)}

A DEM of the study area of AWiFS and part of MODIS was generated using a 1:50 000 toposheet at $40 \mathrm{~m}$ contour level. The Shuttle Radar Topography Mission (SRTM) data of the DEM at $90 \mathrm{~m}$ spatial resolution were also used for certain regions of the study area on MODIS images. The non-linear interpolation function is used for three-dimensional (3-D) surface generation. The grid resolution of the DEM is $6 \mathrm{~m}$ and $90 \mathrm{~m}$ which were further resampled at 56 and $500 \mathrm{~m}$ to make it equal to the grid resolution of AWiFS and MODIS satellite images respectively. Thereafter, the DEM was used to generate terrain parameters for topographic models using ERDAS Imagine 8.7.

\section{TESTING AND EVALUATION \\ Qualitative visual performance}

The performance of the following algorithms for topographic corrections was analysed qualitatively and quantitatively: C-corrections, Minnaert methods (including the slope in Equation (5)) and slope-matching technique. The values of the coefficients estimated for C-corrections $\left(c_{\lambda}\right)$, Minnaert constant, $k(\lambda)$ and slope-matching parameter (methods) $\left(C_{\lambda}\right)$ are given in Table 4 . The values of these coefficients are different for different satellite data in different spectral bands of AWiFS and MODIS, thereby
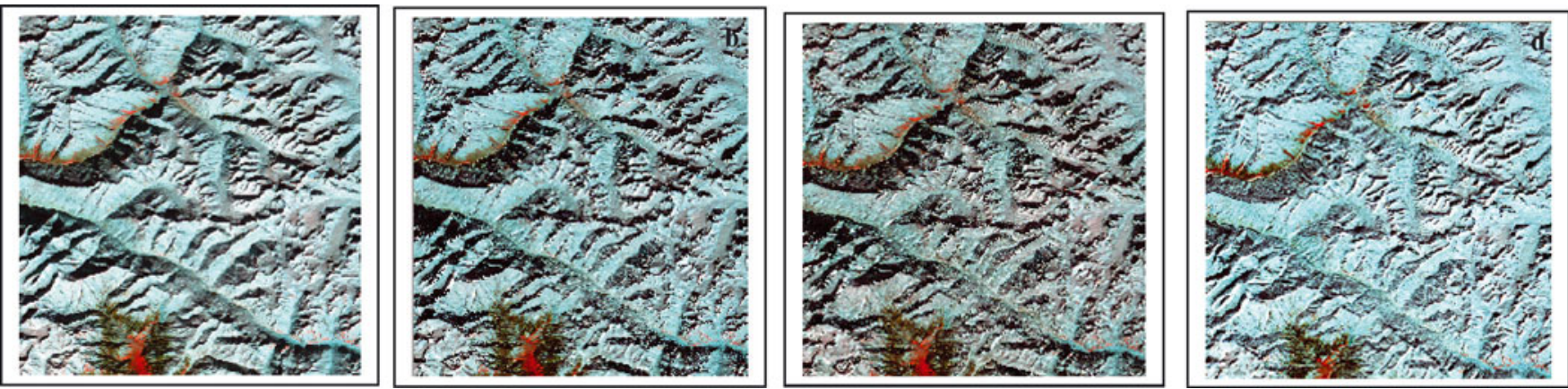

Fig. 2. Topographically corrected image of AWiFS: (a) C-correction; (b) Minnaert correction (Equation (4)); (c) Minnaert method (Equation (5)); and (d) slope match method. 

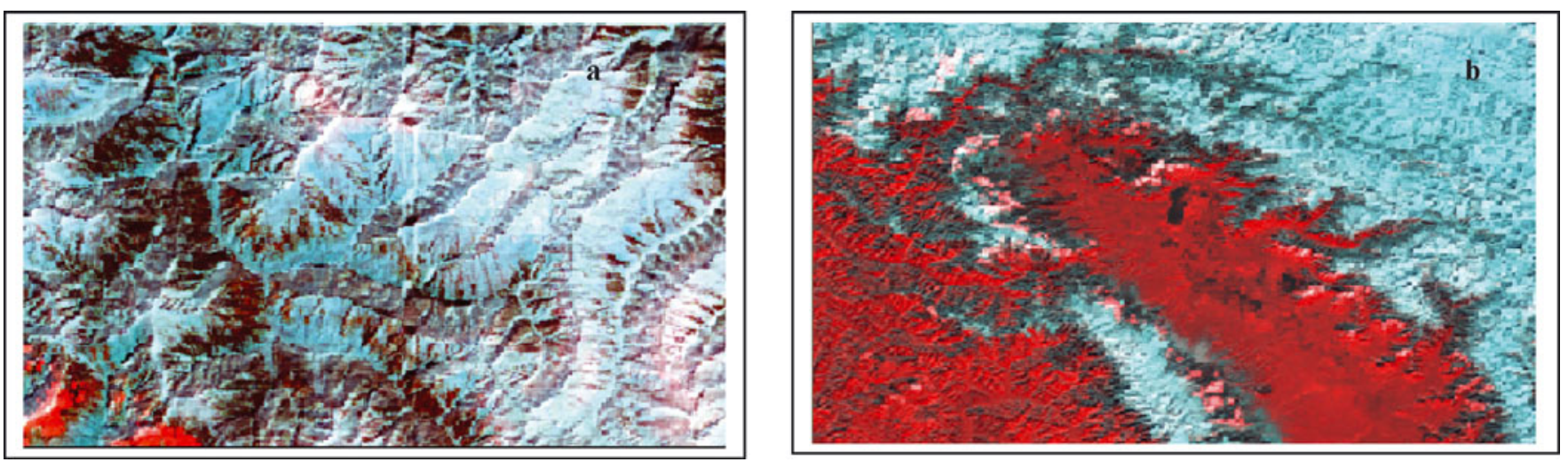

Fig. 3. Topographic correction results by slope match method: (a) AWiFS, 26 February 2005; (b) MODIS, 19 January 2005.

confirming the necessity for their estimation for each image in view of varying illumination. The Minnaert constant shows completely non-Lambertian behavior for the Himalayan terrain.. The comparative visual analysis for one of the results of AWiFS (8 January 2009) obtained using different topographic methods (using Equations (3-6)) is shown in Figure 2. The topographic results obtained using the slopematching method for AWiFS (26 February 2005) and MODIS (19 January 2005) are also shown in Figure 3. The visual effect is more impressive in slope match (Figs $2 \mathrm{~d}$ and $3 \mathrm{a}$ and $\mathrm{b}$ ) as compared to other results (Fig. 2a-c). The 3 -D relief effect is minimized and shows flat representation of the terrain. The appearance of land cover becomes much more independent of topography than in the original uncorrected bands (Fig. 2a). The topographical results obtained using C- and Minnaert corrections do not improve the visual results, and 3-D relief effects are still evident. The results of the first stage of the slope-matching method are shown in Figure 4. The best 3-D visual appearances are observed on the MODIS imagery (Fig. 4c) as compared to AWiFS imagery (Fig. 4a and b) in first-stage results. The shadow is almost completely removed. The geomorphology and terrain features of the image are also enhanced as compared to the original image. In order to confirm the actual land cover after topographic corrections, especially in shady areas, the results are compared with the normalized difference snow index (NDSI). NDSI is estimated for AWiFS and MODIS (Hall and others, 1995), and the thematic results are shown in the Figure 5. NDSI can retrieve information under mountain shadow. Its values vary from -1 to +1 and are positive for snow (white area in
Fig. 5) and negative for non-snow area (black colour in Fig. 5). The comparative analysis of Figure 3 with Figure 5 shows that slope matching is the only method that retrieves the true information under shadow.

\section{Quantitative analysis}

To evaluate the model quantitatively, firstly, we estimated the typical mean values of spectral reflectance of the snow samples from the radiometrically corrected (atmospheric correction and topographic normalization) and uncorrected images on the south (Sun-facing) and north (shady slopes) aspect in all AWiFS and MODIS bands as shown in Table 5. These results suggest that in the uncorrected images the apparent reflectance of snow on the shady slope is very low. This is obviously untrue since it is known that snow reflectance is very high in visible bands (Fig. 6). The low values can be attributed to shadowing effects on shady slopes. Secondly, if the topographic corrections are successful, the mean values of snow samples on the shady slopes (north aspect) should increase while those of sunny slopes should decrease. It is observed from Table 5 that, although all the topographic methods satisfy the above-mentioned criterion, the corrected values of reflectance for snow samples on the north aspect using C- and Minnaert corrections (including slope) are not comparable to the typical true values. If the shady and Sun-facing slopes have the same snow cover, the spectral reflectance of snow should be homogeneous. After atmospheric correction and topographic normalization, the snow reflectance on shady slopes is observed to show the true situation in slopematching method only.
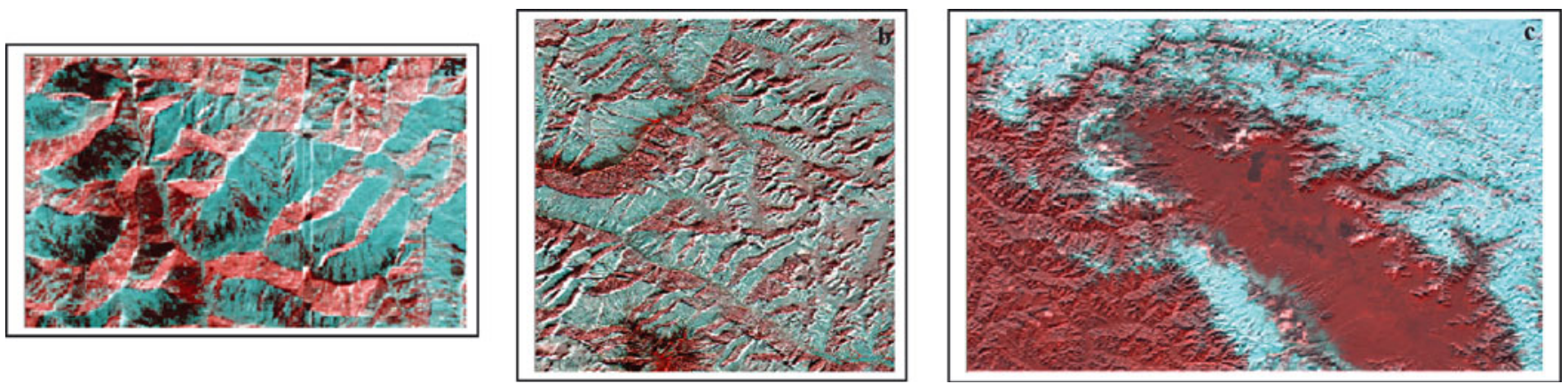

Fig. 4. First-stage normalization image of slope match for visual interpretation of topographical features: (a, b) AWiFS and (c) MODIS. 

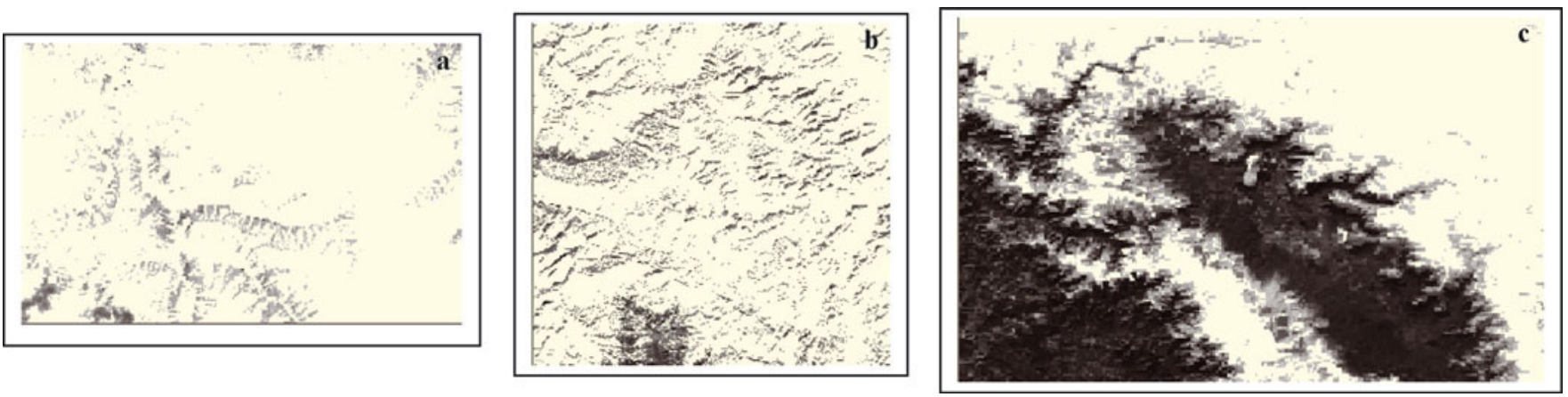

Fig. 5. NDSI image showing snow area (white: NDSI $\geq 0.6$ ): (a) AWiFS, 26 February 2005; (b) AWiFS, 8 January 2009; and (c) MODIS, 19 January 2005

\section{Validation}

Topographical results for all the images are validated with in situ observations of spectral reflectance of snow recorded at different geolocation points using the optical spectroradiometer at the time of satellite pass in real time in the wavelength range $350-2500 \mathrm{~nm}$. The mean curves for three different dates of satellite pass are shown in Figure 6. The mean values from the field observations (Fig. 6) were obtained in the respective spectral bands of AWiFS and MODIS (Table 6). The comparison of field results with satellite-estimated reflectance values before and after the topographic corrections in Table 6 shows that all the methods except slope match underestimate the reflectance values. The inference from Table 6 is that the mean reflectance values of snow samples of an entire image and on the south and north aspects are comparable only in slope-matching method. This is possible only when information is retrieved under the shadow area.

\section{Graphical analysis}

The topographic corrections were also evaluated using graphical analysis of spectral reflectance with IL both before and after the corrections. The visible band reflectance of AWiFS (B2) and MODIS (B3) with IL are shown in Figure 7. The results suggest that reflectance changes with IL for the uncorrected image of AWiFS (Fig. 7a and e) but, after the topographic corrections are carried out, it remains constant with different values of IL. On the other hand, uncorrected reflectance in MODIS with different values of IL (Fig. 7i) does not show much variation with IL. These results suggest that MODIS imagery does not require topographic corrections since all the topographic models show satisfactory results for Himalayan terrain. By contrast, the integrated analysis of different topographic results as discussed earlier suggests that the slope-matching method is most suitable for Himalayan terrain and that topographic corrections are

Table 5. Mean values of spectral reflectance of snow samples in AWiFS and MODIS bands, and values on the north and south aspects of an entire image

AWiFS, 26 February 2005

AWiFS, 8 January 2009

MODIS, 19 January 2005

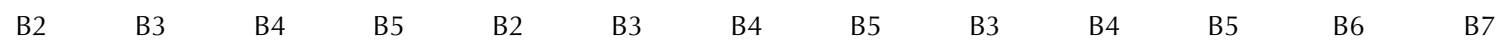
$(520-\quad(620-\quad(770-\quad(1550-\quad(520-\quad(620-\quad) \quad(770-\quad(1550-\quad(459-\quad) \quad(545-\quad(1230-\quad(1628-\quad(2105-$ $590 \mathrm{~nm}) 680 \mathrm{~nm}) 860 \mathrm{~nm}) 1700 \mathrm{~nm}) 590 \mathrm{~nm}) 680 \mathrm{~nm}) 860 \mathrm{~nm}) 1700 \mathrm{~nm}) 479 \mathrm{~nm}) 565 \mathrm{~nm}) 1250 \mathrm{~nm}) 1652 \mathrm{~nm}) 2155 \mathrm{~nm})$

\begin{tabular}{|c|c|c|c|c|c|c|c|c|c|c|c|c|c|}
\hline \multicolumn{14}{|c|}{ Original image } \\
\hline Mean & 0.545 & 0.547 & 0.553 & 0.052 & 0.645 & 0.634 & 0.626 & 0.111 & 0.598 & 0.567 & 0.354 & 0.085 & 0.038 \\
\hline South aspect & 0.750 & 0.753 & 0.749 & 0.059 & 0.859 & 0.854 & 0.853 & 0.152 & 0.712 & 0.695 & 0.444 & 0.110 & 0.048 \\
\hline North aspect & 0.325 & 0.325 & 0.334 & 0.039 & 0.392 & 0.0 .373 & 0.359 & 0.066 & 0.480 & 0.437 & 0.269 & 0.064 & 0.031 \\
\hline \multicolumn{14}{|l|}{ C-correction } \\
\hline Mean & 0.596 & 0.597 & 0.604 & 0.056 & 0.643 & 0.632 & 0.623 & 0.111 & 0.600 & 0.568 & 0.356 & 0.086 & 0.038 \\
\hline South aspect & 0.640 & 0.642 & 0.640 & 0.053 & 0.792 & 0.785 & 0.781 & 0.139 & 0.696 & 0.678 & 0.429 & 0.105 & 0.047 \\
\hline North aspect & 0.545 & 0.546 & 0.555 & 0.054 & 0.437 & 0.418 & 0.402 & 0.075 & 0.494 & 0.452 & 0.282 & 0.069 & 0.032 \\
\hline \multicolumn{14}{|l|}{ Minnaert } \\
\hline Mean & 0.597 & 0.599 & 0.607 & 0.056 & 0.679 & 0.669 & 0.659 & 0.122 & 0.633 & 0.605 & 0.389 & 0.095 & 0.042 \\
\hline South aspect & 0.667 & 0.670 & 0.665 & 0.055 & 0.741 & 0.728 & 0.721 & 0.131 & 0.644 & 0.616 & 0.419 & 0.106 & 0.048 \\
\hline North aspect & 0.538 & 0.539 & 0.554 & 0.056 & 0.558 & 0.548 & 0.529 & 0.105 & 0.635 & 0.607 & 0.387 & 0.095 & 0.041 \\
\hline \multicolumn{14}{|c|}{ Minnaert including slope } \\
\hline Mean & 0.567 & 0.569 & 0.576 & 0.052 & 0.621 & 0.615 & 0.608 & 0.109 & 0.578 & 0.556 & 0.358 & 0.087 & 0.038 \\
\hline South aspect & 0.636 & 0.638 & 0.634 & 0.0513 & 0.663 & 0.655 & 0.650 & 0.117 & 0.604 & 0.581 & 0.397 & 0.100 & 0.046 \\
\hline \multicolumn{14}{|l|}{ Slope match } \\
\hline Mean & 0.743 & 0.745 & 0.748 & 0.064 & 0.829 & 0.826 & 0.817 & 0.154 & 0.712 & 0.693 & 0.431 & 0.103 & 0.053 \\
\hline South aspect & 0.749 & 0.752 & 0.748 & 0.059 & 0.853 & 0.849 & 0.847 & 0.152 & 0.700 & 0.682 & 0.438 & 0.108 & 0.063 \\
\hline North aspect & 0.754 & 0.755 & 0.755 & 0.065 & 0.786 & 0.782 & 0.766 & 0.151 & 0.711 & 0.692 & 0.421 & 0.099 & 0.046 \\
\hline
\end{tabular}




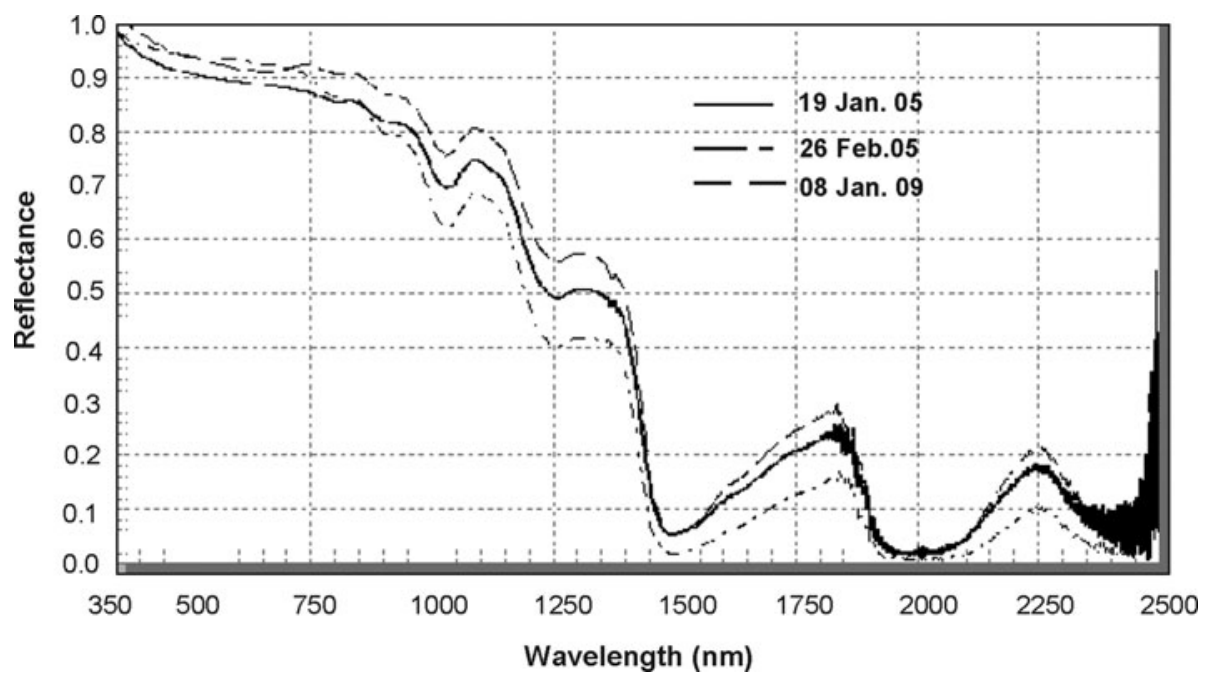

Fig. 6. In situ observations of spectral reflectance characteristics of pure snow at the time of satellite pass.

required for MODIS images and for visual interpretation and quantitative analysis of snow-cover applications.

\section{CONCLUSIONS}

The present paper discusses qualitative and quantitative analysis of different topographic correction methods on AWiFS and MODIS satellite data. The first stage of the slope-matching method shows excellent 3-D terrain geomorphology by removing the topographical relief effect, especially in MODIS data. Three-dimensional relief effects are minimized only in the slope-matching method and show flat representation of the terrain. The C-correction and Minnaert methods are not very successful and produce poor results. The Minnaert method also shows completely nonLambertian behaviour of the Himalayan terrain. The slopematching method has advantages in the true quantitative retrieval of spectral reflectance, especially in shady area, compared to C-correction and Minnaert methods.

\section{ACKNOWLEDGEMENTS}

The authors thank R.N. Sarwade (Director SASE) for kind permission to submit the paper. Thanks are also due to the

Table 6. Validation of topographic normalization models with field results of spectral reflectance using spectroradiometer

B2 $(520-590 \mathrm{~nm}) \quad$ B3 $(620-680 \mathrm{~nm}) \quad$ B4 $(770-860 \mathrm{~nm}) \quad$ B5 $(1550-1700 \mathrm{~nm})$

AWiFS, 26 Feb. 2005; pixel location: lat. 34.6253, long. 74.4146; slope $15.9^{\circ}$

Original image

0.889

0.889

C-correction

0.778

0.778

0.805

Minnaert

0.805

0.790

0.790

0.910

Slope match

0.911

0.926

$\begin{array}{ll}0.869 & 0.073 \\ 0.763 & 0.066 \\ 0.787 & 0.068 \\ 0.773 & 0.067 \\ 0.891 & 0.074 \\ 0.88 & 0.06\end{array}$

AWiFS, 8 Jan. 2009; pixel location: lat. 32.3564, long. 77.1252; slope $18.2^{\circ}$

Original image

$0.903 \quad 0.878$

0.878

$\begin{array}{ll}0.849 & 0.823 \\ 0.826 & 0.813\end{array}$

Minnaert

$\begin{array}{ll}0.776 & 0.747\end{array}$

0.747

0.936

0.934

0.940

0.141

Minnaert including slope

0.937

0.879

0.141

$0.804-0.131$

$0.796 \quad 0.121$

Field results

0.934

0.146

0.912

0.145

\section{MODIS band}
B3
B4
B5
B6
B7

MODIS, 19 Jan. 2005; pixel location: lat. 34.6574, long. 74.3983 ; slope $19.9^{\circ}$

\begin{tabular}{|c|c|c|c|c|c|}
\hline Original image & 0.969 & 0.989 & 0.704 & 0.186 & 0.075 \\
\hline C-correction & 0.953 & 0.970 & 0.686 & 0.180 & 0.075 \\
\hline Minnaert & 0.907 & 0.912 & 0.657 & 0.169 & 0.070 \\
\hline Minnaert including slope & 0.885 & 0.892 & 0.629 & 0.165 & 0.067 \\
\hline Slope match & 0.948 & 0.865 & 0.703 & 0.187 & 0.096 \\
\hline Field results & 0.921 & 0.900 & 0.50 & 0.129 & 0.070 \\
\hline
\end{tabular}



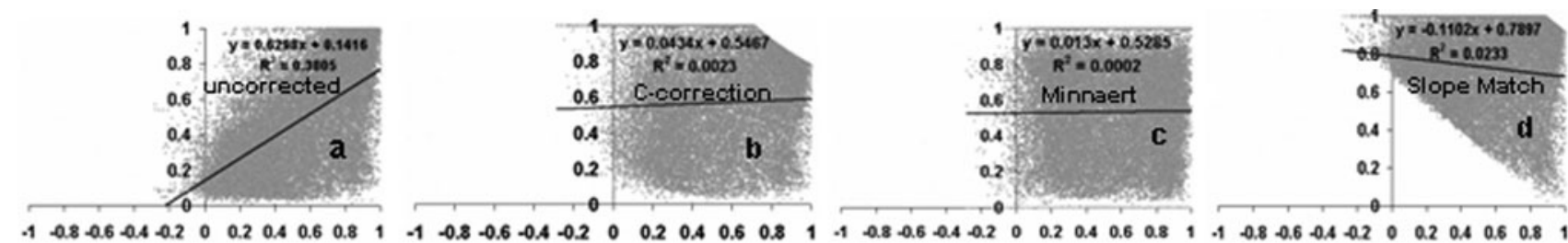

$\begin{array}{cccccccccccc}-1 & 0.8 & -0.6 & -0.4 & 0.2 & 0 & 0.2 & 0.4 & 0.6 & 0.8 & 1\end{array}$
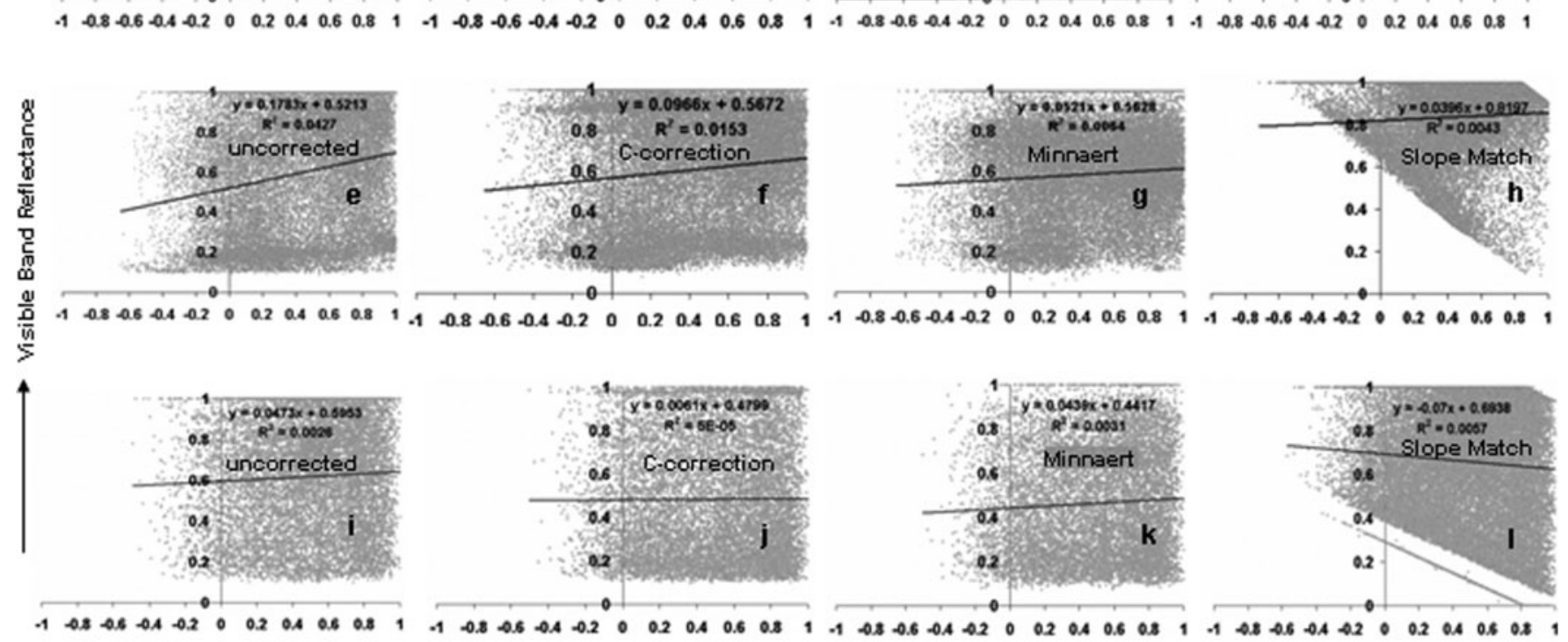

$\operatorname{Cos}(\mathbf{i})$

Fig. 7. Graphical analysis of reflectance in visible band with illumination before and after topographic corrections using different methods: (a-d) AWiFS, 26 February 2005; (e-h) AWiFS, 8 January 2009; and (i-I) MODIS, 19 January 2005.

internal SASE committee for reviewing it before submission. We acknowledge the valuable critical review by two anonymous reviewers for significant improvement of the paper.

\section{REFERENCES}

Chavez, P.S.J. 1989. Radiometric calibration of Landsat thematic mapper multispectral images. Photogramm. Eng. Remote Sens., 55(9), 1285-1294.

Civco, D. 1989. Topographic normalization of Landsat thematic mapper imagery. Photogramm. Eng. Remote Sens., 55(9), 1303-1309.

Colby, J.D. 1991. Topographic normalization in rugged terrain. Photogramm. Eng. Remote Sens., 57(5), 531-537.

Dozier, J. and D. Marks. 1987. Snow mapping and classification from Landsat Thematic Mapper data. Ann. Glaciol., 9, 97-103.

Hall, D.K., G.A. Riggs and V.V. Salomonson. 1995. Development of methods for mapping global snow cover using Moderate Resolution Imaging Spectroradiometer (MODIS) data. Remote Sens. Environ., 54(2), 127-140.

Holben, B. and C. Justice. 1980. The topographic effect on spectral response from nadir pointing sources. Photogramm. Eng. Remote Sens., 46(9), 1191-1200.

Kasten, F. 1962. Table of solar altitudes for geographical effect on spectral response from nadir pointing sources. CRREL Spec. Rep. 57.

Liu, Y., Y. Noumi and Y. Yamaguchi. 2009. Discrepancy between ASTER- and MODIS-derived land surface temperatures: terrain effects. Sensors, 9(2), 1054-1066.

Minnaert, M. 1941. The reciprocity principle in lunar photometry. Astrophys. J., 93, 403-410.

Mishra, V.D., H.S. Negi, A.K. Rawat, A. Chaturvedi and R.P. Singh. 2009. Retrieval of sub-pixel snow cover information in the Himalayan region using medium and coarse resolution remote sensing data. Int. J. Remote Sens., 30(18), 4707-4731.
Moran, M.S., R.D. Jackson, P.N. Slater and P.M. Teillet 1992. Evaluation of simplified procedures for retrieval of land surface reflectance factors from satellite sensor output. Remote Sens. Environ., 41(2-3), 169-184.

Nichol, J., L.K. Hang and W.M. Sing. 2006. Empirical correction of low Sun angle images in steeply sloping terrain: a slopematching technique. Int. J. Remote Sens., 27(3), 629-635.

Pandya, M.R., R.P. Singh, K.R. Murali, P.N. Babu, A.S. Kirankumar and V.K. Dadhwal. 2002. Bandpass solar exoatmospheric irradiance and Rayleigh optical thickness of sensors on board Indian remote sensing satellites-1B, $-1 \mathrm{C},-1 \mathrm{D}$, and $\mathrm{P} 4$. IEEE Trans. Geosci. Remote Sens., 40(3), 714-718.

Riaño, D., E. Chuvieco, J. Salas and I. Aguado. 2003. Assessment of different topographic corrections in Landsat-TM data for mapping vegetation areas. IEEE Trans. Geosci. Remote Sens., 41(5), 1056-1061.

Richter, R. 1998. Correction of satellite imagery over mountainous terrain. Appl. Opt., 37(18), 4004-4015.

Sandmeier, S.R. 1995. A physically-based radiometric correction model - correction of atmospheric and illumination effects in optical satellite data of rugged terrain. (PhD thesis, University of Zürich.)

Shepherd, J.D. and J.R. Dymond. 2003. Correcting satellite imagery for the variance of reflectance and illumination with topography. Int. J. Remote Sens., 24(17), 3503-3514.

Song, C., C.E. Woodcock, K.C. Seto, M.P. Lenney and S.A. Macomber. 2001. Classification and change detection using Landsat TM data: when and how to correct atmospheric effects? Remote Sens. Environ., 75(2), 230-244.

Teillet, P.M., B. Guindon and D.G. Goodenough. 1982. On the slope-aspect correction of multispectral scanner data. Can. J. Remote Sens., 8(2), 84-106.

Van der Meer, F. 1996. Spectral mixture modelling and spectral stratigraphy in carbonate lithofacies mapping. ISPRS J. Photogramm. Rem. Sens., 51(3), 150-162. 